\title{
PARTIAL DISTAL 12q TRISOMY WITH ARACHNOID CYST
}

\author{
Mitsuo Masuno, Yoshimitsu Fukushima, Yoshitsugu Sugio, \\ and Yoshikazu KurokI \\ Division of Medical Genetics, Kanagawa Children's Medical \\ Center, Yokohama 232, Japan
}

\begin{abstract}
Summary A three-year-old boy with partial distal 12q trisomy, 46,XY, $\operatorname{der}(9), \mathrm{t}(9 ; 12)(\mathrm{q} 34.3 ; \mathrm{q} 24.31) \mathrm{mat}$, is described. To our best knowledge, this is the second case in Japan. He has an arachnoid cyst, which has not yet been described in the literature.
\end{abstract}

\section{INTRODUCTION}

There has been 14 reports ( 16 cases) of partial distal 12q trisomy (Aurias et al., 1978; de Muelenaere et al., 1980; Harrod et al., 1980; Hemming and Brown, 1979; Hirschhorn et al., 1973; Hobolth et al., 1974; Ieshima et al., 1984; Melnyk et al., 1981; Pratt and Bulugahapitiya, 1983; Prieur et al., 1977; Robert et al., 1981; Tajara et al., 1985; Tengström et al., 1985; Zabel and Baumann, 1981). Here we report an additional case of partial distal $12 \mathrm{q}$ trisomy which was detected by high resolution chromosome banding technique and review the previously reported patients.

\section{CASE REPORT}

The proband was the first product of 28-year-old mother and 30-year-old father, who were unrelated. Because of placental dysfunction, caesarean section was performed at 40 weeks of gestation. Birth weight was $2,055 \mathrm{~g}$, the length $44.2 \mathrm{~cm}$, and the head circumference $31.0 \mathrm{~cm}$. The early neonatal period was complicated with hyperbilirubinemia, hypoglycemia and feeding difficulties. He had also retinopathy of prematurity. He controlled his head at 6 months of age, rolled over at 9 months, and sat alone at 1 year 2 months. At the age of 3 years 1 month, his body weight was $10.9 \mathrm{~kg}(-1.8 \mathrm{SD})$, the length $90.3 \mathrm{~cm}(-0.7 \mathrm{SD})$, and the head circumference $44.4 \mathrm{~cm}(-3.5 \mathrm{SD})$. His muscle tone was decreased. Main clinical features were severe mental retardation (DQ 23), microcephaly, brachycephaly, flat facial profile, 
hypertelorism, antimongoloid slant, blepharoptosis, broad eyebrows, flat nasal bridge, anteverted nares, long philtrum, carp mouth, pointed chin, short tapering fingers, and overlapping toes (Fig. 1).

Dermatoglyphics was abnormal; low TFRC(47) and bilateral absent digital triradius c. Sydney line was noted on the left hand (Table 1). Skeletal survey revealed normal. IVP was normal. CT scan of the brain showed an arachnoid cyst at the left middle cranial fossa, mild dilatation of the lateral ventricles, and asymmetrical Sylvian fissures (Fig. 2). EEG was normal.
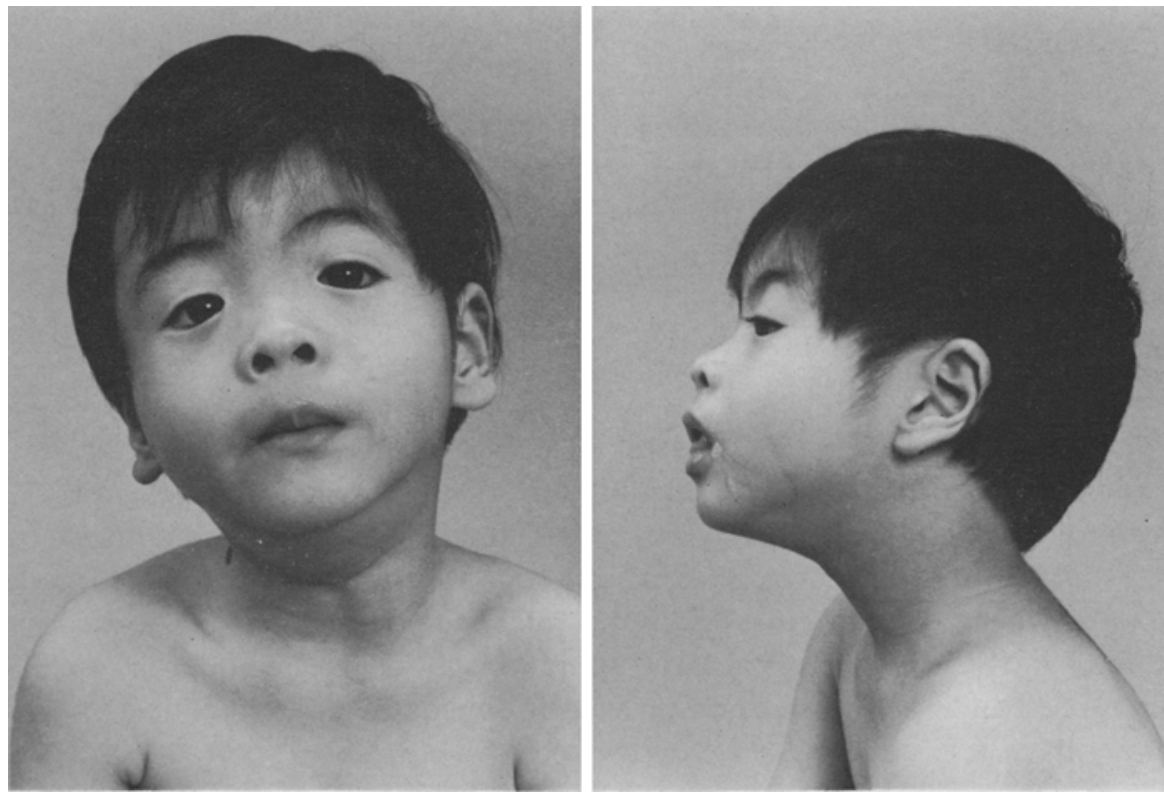

Fig. 1. The patient at 3 years of age.

Table 1. Dermatoglyphic findings of the proband.

\begin{tabular}{lccccc}
\hline & 1 & 2 & 3 & 4 & 5 \\
\hline Left hand & $\mathrm{U}$ & $\mathrm{T}$ & $\mathrm{U}$ & $\mathrm{U}$ & $\mathrm{U}$ \\
Right hand & $\mathrm{U}$ & $\mathrm{U}$ & $\mathrm{U}$ & $\mathrm{U}$ & $\mathrm{U}$ \\
\hline Palmar formula & & & & \\
Left: & $11.0 .7 .3 .13^{\prime}$ & $-\mathrm{t}^{\prime}$ & -0.0 .0 .0 .0 .0$. & & \\
Right: & $11.0 .7 .3 .13^{\prime}$ & $-\mathrm{t}^{\prime}$ & -0.0 .0 .0 .0 .0$. & \\
\hline
\end{tabular}

$\mathrm{U}$, ulnar loop; $\mathrm{T}$, tented arch.

Jpn. J. Human Genet. 


\section{CYTOGENETIC FINDINGS}

The karyotype of the proband was $46, X Y, \operatorname{der}(9), t(9 ; 12)(q 34.3 ; q 24.31)$ mat. The mother's karyotype was $46, \mathrm{XX}, \mathrm{t}(9 ; 12)(\mathrm{q} 34.3 ; \mathrm{q} 24.31)$. The father showed normal male karyotype (Fig. 3).

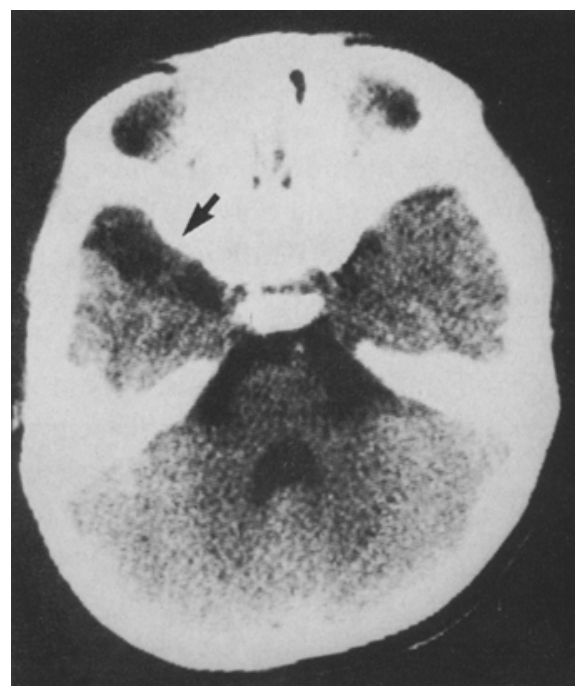

Fig. 2. CT scan of the brain at 3 years of age. The arrow indicates the arachnoid cyst.

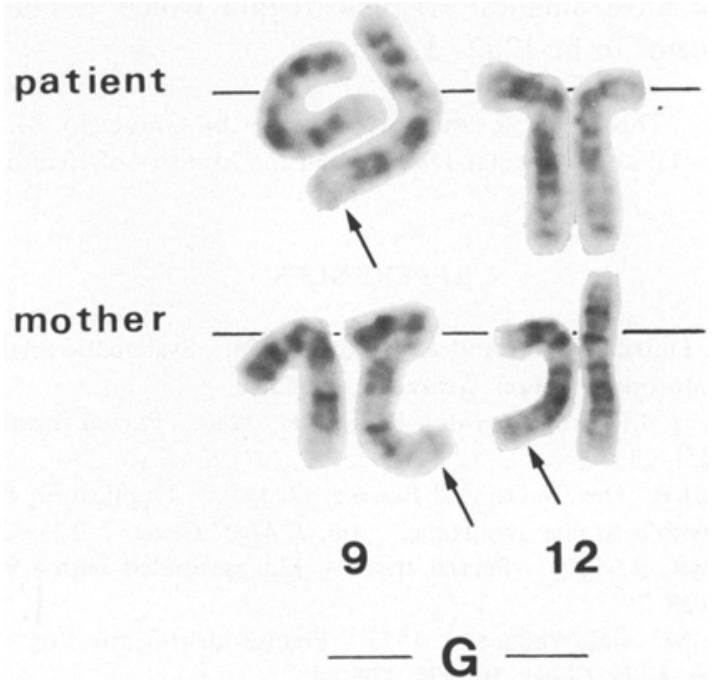

Fig. 3. Partial karyotype of the proband and his mother with high resolution $G$ banding. Breakpoints are at $9 \mathrm{q} 34.3$ and at $12 \mathrm{q} 24.31$. 


\section{DISCUSSION}

Partial distal $12 \mathrm{q}$ trisomy is characterized by mental retardation, growth retardation, dyscephaly (dolichocephaly or brachycephaly), hypertelorism, flat nasal bridge, low-set ears, poor lobulation, down-turned mouth, micrognathia or pointed chin, short neck, loose skin at nape, wide set nipples, simian creases, genitourinary anomalies, sacrococcygeal dimple, and heart defect. Although the present case showed almost similar craniofacial features, visceral anomalies and sacrococcygeal anomalies were not observed.

CT findings in 5 previous cases included frontal lucent areas, mild hydrocephaly, cortical atrophy, dilated third and/or lateral ventricles and cisterna magna. Two autopsy clarified dysplasia of cerebellar dentate nucleus, hydrocephaly, and brain malformation. An arachnoid cyst, noticed in the present case, has not been described so far.

Fourteen out of 17 cases, including ours, resulted from malsegregation of parental translocation (10 maternal, 4 paternal). The $12 \mathrm{q}$ segment was translocated to a different chromosome; 9(five cases), 4(three cases), 2(two cases), 17(two cases), 18(one case), 21(one case). The remaining two cases had an intrachromosomal duplication (Harrod et al., 1980). One case had an inverted duplication (Ieshima et al., 1984). Trisomic segments described in the present case and the previous reports are variable; $12 \mathrm{q} 24 \rightarrow$ qter(four cases), $12 \mathrm{q} 24.1 \rightarrow$ qter(two cases), $12 \mathrm{q} 24.13 \rightarrow$ qter(one case), $\quad 12 \mathrm{q} 24.2 \rightarrow$ qter(two cases), $\quad 12 \mathrm{q} 24.3 \rightarrow$ qter(two cases), $12 \mathrm{q} 24.31 \rightarrow$ qter(two cases), $\quad 12 \mathrm{q} 24.1 \rightarrow \mathrm{q} 24.33$ (two cases), $12 \mathrm{q} 12 \rightarrow$ qter(one case), $12 \mathrm{q} 21.2 \rightarrow$ qter(one case). The most smallest trisomic region which is compatible with $12 \mathrm{q}$ trisomy syndrome seems to be $12 \mathrm{q} 24.3$.

Acknowledgments This study was supported in part by Grant No. 85-07-17 from National Center for Nervous, Mental and Muscular Disorders of the Ministry of Health and Welfare, Japan.

\section{REFERENCES}

Aurias, A., Prieur, M., Dutrillaux, B., and Lejeune, J. 1978. Systematic analysis of 95 reciprocal translocations of autosomes. Hum. Genet. 45: 259-282.

de Muelenaere, A., Fryns, J.P., and Van den Berghe, H. 1980. Partial distal 12q trisomy. Ann. Genet. (Paris) 23: 251-253.

Harrod, M.J.E., Byrne, J.B., Dev, V.G., and Franke, U. 1980. Duplication 12q mosaicism in two unrelated patients with a similar syndrome. Am. J. Med. Genet. 7: 123-129.

Hemming, L. and Brown, R. 1979. Partial trisomy 12q associated with a familial translocation. Clin. Genet, 16: 25-28.

Hirschhorn, K., Lucas, M., and Wallace, I. 1973. Precise identification of various chromosomal abnormalities. Ann. Hum. Genet. 36: 375-379.

Hobolth, N., Jacobsen, P., and Mikkelsen, M. 1974. Partial trisomy 12 in a mentally retarded boy and translocation $(12 ; 21)$ in his mother. $J$. Med. Genet. 11: 299-303. 
Ieshima, A., Yorita, T., Ohta, S., and Kuroki, Y. 1984. A female infant with pure duplication 12q24.2 $\rightarrow$ qter. Jpn. J. Human Genet. 29: 391-397.

Melnyk, A.R., Weiss, L., Van Dyke, D.L., and Jarvi, P. 1981. Malformation syndrome of duplication $12 \mathrm{q} 24.1 \rightarrow$ qter. Am. J. Med. Genet. 10: 357-365.

Pratt, N.R. and Bulugahapitiya, D.T.D. 1983. Partial trisomy $12 \mathrm{q}$ : a clinically recognizable syndrome. Genetic risks associated with translocations of chromosome 12q. J. Med. Genet. 20 : $86-89$.

Prieur, M., Couturier, J., Herrault, A., Lepintre, J., and Lejeune, J., Cited in Rethoré, M. 1977. Syndromes involving chromosomes 4, 9, and 12. In New Chromosomal Syndromes, Yunis, J.J., ed., Academic Press, New York, pp. 119-183.

Robert, S.H., Mattina, T., Laurence, K.M., Sorge, G., and Pavone, L. 1981. Partial trisomy 12q: report of a case and review. J. Med. Genet. 18: 470-473.

Tajara, E.H., Varella-Garcia, M., and Gusson, A.C.T. 1985. Partial trisomy 12q24.31 $\rightarrow$ qter, J. Med. Genet. 22: 73-76.

Tengström, C., Wilska, M., Kähkönen, M., and Leisti, J. 1985. Partial trisomy 12q: clinical and cytogenetic observations. Clin. Genet. 28: 112-117.

Zabel, B. and Baumann, W. 1981. Partial trisomy 12q. J. Med. Genet. 18: 144-146. 